\title{
Respiratory Biogenesis during the Cell Cycle of Aerobically Grown Escherichia coli K 12. The Accumulation and Ligand Binding of Cytochrome o
}

\author{
By ROBERT I. SCOTT, ${ }^{1}$ ROBERT K. POOLE ${ }^{1 *}$ \\ AND BRITTON CHANCE ${ }^{2}$ \\ ${ }^{1}$ Department of Microbiology, Queen Elizabeth College (University of London), \\ Campden Hill, London W8 $7 A H$ \\ ${ }^{2}$ Johnson Research Foundation, Department of Biochemistry and Biophysics, \\ University of Pennsylvania, Philadelphia, Pennsylvania 19104, U.S.A.
}

(Received 11 August 1980)

\begin{abstract}
A quantitative assay is described for the measurement of cytochrome $o$ in intact cells of $E$. coli. The procedure involves flash photolysis of the CO-liganded, reduced enzyme in the absence of $\mathrm{O}_{2}$ at temperatures (approx. $-100^{\circ} \mathrm{C}$ ) at which the rate of recombination of $\mathrm{CO}$ is immeasurably slow. Other CO-binding pigments known to be present, particularly cytochrome $d$, are excluded from the photodissociation spectrum under these conditions. Measurement of the content of cytochrome $o$ in bacteria separated into size (and thus age) classes by zonal centrifugation shows that the cytochrome accumulates continuously, probably exponentially, throughout the cell cycle and thus constitutes a constant proportion of cell protein during the cycle. The velocity of recombination of $\mathrm{CO}$ with cytochrome $o$ at $-65^{\circ} \mathrm{C}$ is invariant over the cell cycle.
\end{abstract}

\section{INTRODUCTION}

Recognition of the diversity of functions performed by the bacterial cytoplasmic membrane has led to many studies of its mode of synthesis during the cell cycle, with conflicting results. In Escherichia coli, the rates of synthesis of various membrane proteins and lipids have been shown to be either continuous or discontinuous (for a review, see Poole, 1980).

Ohki (1972) reported that the amount of 'cytochrome $b_{1}$ ' (measured as the difference in absorption between 560 and $575 \mathrm{~nm}$ in room temperature reduced minus oxidized difference spectra) increased in discrete steps in synchronous cultures of $E$. coli. The steps were coincident with increases in transport activity and lipid turnover. However, several considerations have led us to re-examine the pattern of cytochrome accumulation in the $E$. coli cell cycle. First, in a recent study by Lutkenhaus et al. (1979), no protein could be identified (of about 750 polypeptides separated on two-dimensional gels) that was synthesized at different rates during different parts of the cell cycle. Although it is possible that appropriate patterns of protein turnover could result in discontinuous accumulation, even though synthesis were continuous, the calculated half-lives of individual proteins in $E$. coli (Mosteller et al.. 1980) appear to be long ( 2 to $23 \mathrm{~h}$ ). It is also possible that cytochromes were not detected in the gels examined by Lutkenhaus et al. (1979). Second, the designation by Ohki (1972) of the $560 \mathrm{~nm}$ absorption band as due to 'cytochrome $b_{1}$ ' is a gross oversimplification of the composition of this band. At least five components are present including cytochrome $o$ (Shipp, 1972), at least under aerobic growth conditions (Scott \& Poole, 1980). Third, the temperature shock procedure used by Ohki (1972) to prepare synchronous cultures might itself have resulted in the observed stepwise pattern of membrane synthesis. 
We have chosen for this study the major terminal oxidase of aerobically grown $E$. coli (Castor \& Chance, 1959), cytochrome $o$. This protein is well suited to our purposes, since it can be assayed without interference from other components in photodissociation spectra of intact bacterial cells (Chance, 1953a) without recourse to cell disruption and protein fractionation under disaggregating conditions. For reasons given previously by others (Koch \& Blumberg, 1976) and ourselves (Scott et al., 1980), cell cycle analysis has been performed by directly fractionating asynchronous cultures into age classes by zonal centrifugation.

In this paper, we describe the accumulation of cytochrome $o$ during the cell cycle and also report on the rate of ligand binding to the oxidase.

\section{METHODS}

Organism, growth conditions and cell cycle analysis. Escherichia coli $\mathrm{K} 12$ (strain A1002) was grown aerobically in a defined medium containing $40 \mathrm{~mm}$-sodium succinate as sole carbon source, exactly as described by Scott et al. (1980). Cells were harvested towards the end of the period of exponential growth by continuous-flow centrifugation. Cell cycle analysis was performed at about $4{ }^{\circ} \mathrm{C}$ by separating such cells into size classes by velocity sedimentation in an equivolumetric sucrose gradient (Scott et al., 1980). Successive fractions eluted from the rotor were sampled for determinations of cell numbers and volumes and then diluted with a buffer that contained $50 \mathrm{~mm}$ - Tris/ $/ \mathrm{HCl}, 2 \mathrm{mM}-\mathrm{MgCl}_{2}$ and $1 \mathrm{~mm}$-EGTA (pH 7.4). The cells were pelleted by centrifugation for $15 \mathrm{~min}$ at $15000 \mathrm{rev} \cdot \mathrm{min}^{-1}\left(26000 \mathrm{~g}\right.$ at $\left.r_{\max }\right)$ in the $8 \times 50 \mathrm{ml}$ rotor of an MSE 18 centrifuge. The pellets were resuspended in the same buffer and recentrifuged in the same rotor and at the same speed for $10 \mathrm{~min}$. The volume of buffer used for final suspension of the cells was adjusted such that the number of cells $\mathrm{ml}^{-1}$ fell within a threefold range. A sample $(200 \mu \mathrm{l})$ was removed from each concentrated suspension for the determination of cell numbers and volumes; the remainder was stored at $-196^{\circ} \mathrm{C}$ for cytochrome determinations.

Preparation of cell suspensions for low-temperature spectrophotometry. The method closely followed that of Poole et al. $(1979 a, b)$. Each cell suspension was thawed and gently homogenized with a Teflon-glass homogenizer (A. H. Thomas \& Co., Philadelphia, U.S.A.). Portions $(0.84 \mathrm{ml})$ were pipetted into cuvettes (internal dimensions $16 \times 46 \mathrm{~mm}$; path length $2 \mathrm{~mm}$ ) followed by $0.36 \mathrm{ml}$ ethylene glycol (final concentration $30 \%, \mathrm{v} / \mathrm{v}$ ). The contents of each cuvette were well-mixed by inversion and then reduced by adding a few grains of sodium dithionite and incubating at 30 to $37^{\circ} \mathrm{C}$ for $5 \mathrm{~min}$. The $\mathrm{CO}$ complex was formed by bubbling the reduced cell suspension with a slow, steady stream of $\mathrm{CO}$ for $5 \mathrm{~min}$. Excessive foaming at the top of the cuvette was controlled by use of antifoam spray (A. H. Thomas \& Co.). The cuvette and its contents were incubated in an ethanol/dry ice bath at $-25^{\circ} \mathrm{C}$ for $5 \mathrm{~min}$ and then transferred to a similar bath at $-78^{\circ} \mathrm{C}$ until required for analysis.

Physical methods. Spectra were recorded with a Johnson Foundation dual-wavelength scanning spectrophotometer, developed from an earlier design (Chance \& Graham, 1971). The optical components were in a classical dual-wavelength configuration, light from a $60 \mathrm{~W}$ tungsten halogen bulb being dispersed by orthogonally arranged Bausch \& Lomb monochromators. The emergent light beam from one monochromator was fixed to give the reference wavelength $(575 \mathrm{~nm}$ ) whilst the second beam scanned the selected spectral range (390 to $700 \mathrm{~nm}$ ). The instrument was under the control of a microprocessor that could store up to four different spectra. The output of the microprocessor to an X-Y plotter (Hewlett Packard Moseley Autograf, model 7001 AM) represented the difference between any two of the stored spectra. The cuvette was cooled to the required temperature by a stream of the microprocessor to an X-Y plotter (Hewlett Packard Moseley Autograf, model 7001 AM) represented the thermocouple adjacent to the sample (Chance et al., 1975).

Quantification of cytochrome 0 . The spectrum of the CO-liganded, reduced cell suspension was scanned at about $-100{ }^{\circ} \mathrm{C}$ and stored in one of the memories. The difference between a further scan of this sample and the stored spectrum was plotted to give a CO-reduced minus CO-reduced baseline. Photolysis of the sample in situ was accomplished by 10 flashes of a $200 \mathrm{~J}$ lamp (see Results) and was followed by plotting the difference between the photolysed (= reduced) sample and the stored CO-reduced spectrum. At these low temperatures, the rate of recombination of $\mathrm{CO}$ with the reduced oxidase is immeasurably slow (Poole et al., 1979a,b). Negligible photodissociation was produced by the measuring or reference light beams before photolysis or during subsequent spectral scanning of the cuvette contents. The absorbance change between 415 and $432 \mathrm{~nm}$ was measured in the photolysed minus CO-reduced difference spectrum and corrected for any (small) absorbance difference at these wavelengths in the baseline. The concentration of cytochrome $o$ was estimated using a molar absorption coefficient, $\varepsilon$ (415-432 nm, i.e. peak to trough), of $170 \times 10^{3} 1 \mathrm{~mol}^{-1} \mathrm{~cm}^{-1}$ (Daniel, 1970).

Determination of ligand-binding velocities of cytochrome $o$. This was performed essentially as described above, but the temperature was $-65^{\circ} \mathrm{C}$. The sample was scanned repetitively after photolysis, successive scans being initiated at $70 \mathrm{~s}$ intervals, to yield a "family" of spectra. The logarithm of $\Delta A_{415-432}$ was plotted against time and the half-time of the initial first-order recombination was measured directly (Poole et al., 1979 b. 1980). 
Cell numbers and volumes. These were determined using a Coulter counter and Channelyzer as described earlier (Scott et al., 1980).

Protein determinations. The total protein content of concentrated suspensions of intact cells was determined in $0.5 \mathrm{M}-\mathrm{NaOH}$ extracts as described by Herbert et al. (1971) with dry bovine plasma albumin as standard. Ethylene glycol did not affect the assay.

Chemicals. Carbon monoxide (grade 1-8) was from Airco, Montvale, N.J. 07645. U.S.A., and ethylene glycol from Fisher Scientific Co., Fairlawn, N.J. 07410, U.S.A.

\section{RESULT S}

\section{Properties of the photodissociation spectrum assay for cytochrome $o$}

Cytochrome $o$ is a CO-binding, $b$-type cytochrome (Chance, $1953 b$; Chance $e t a l ., 1953$ ) whose role as a terminal oxidase was established in the classical photochemical action spectra of Castor \& Chance (1959). Photodissociation of the CO-liganded, reduced haemoprotein at temperatures at which recombination of the dissociated ligand is not favoured (Poole et al., $1979 a, b, 1980)$ gave the difference spectrum (with reference to the CO-reduced sample) shown in Fig. 1. This spectrum is the inverse of the more commonly presented 'CO-difference spectrum' (CO-reduced minus reduced). Troughs (due to dissociation of $\mathrm{CO}$ from the cytochrome-CO complex) are observed at $415 \mathrm{~nm}$, at about $535 \mathrm{~nm}$ (broad) and $570 \mathrm{~nm}$. The prominent peak at $432 \mathrm{~nm}$ is due to the reduced form of the oxidase. The inset (Fig. 1) shows that photolysis was essentially complete after 10 flashes of the photolysing lamp. Up to eight further scans after photolysis with 15 flashes revealed no change in the spectral shape or amplitude. The amount of cytochrome $o$ detectable in such photodissociation spectra was $>95 \%$ of that detected in conventional CO-reduced minus reduced difference spectra.

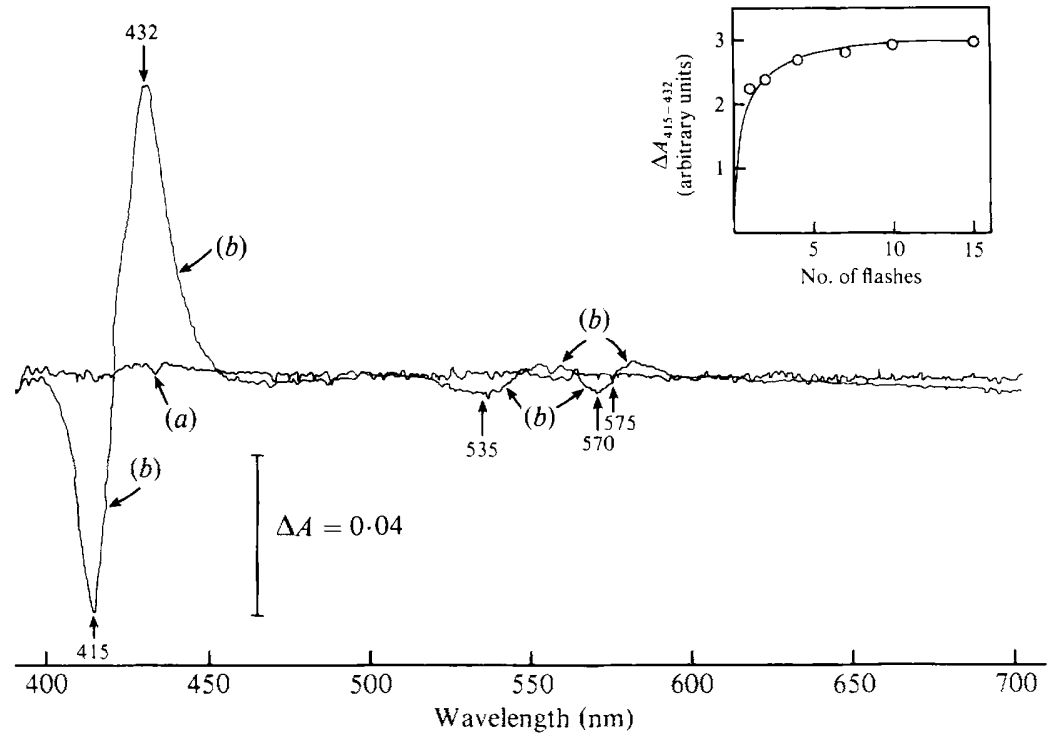

Fig. 1. Photodissociation spectrum of cytochrome $o$ in $E$. coli and the effect of repeated light flashes. The spectrum of a $\mathrm{CO}$-liganded, dithionite-reduced cell suspension was recorded into the digital memory of a dual-wavelength scanning spectrophotometer (reference wavelength. $575 \mathrm{~nm}$ ) at $-103^{\circ} \mathrm{C}$. Trace $(a)$ is the spectrum of the difference between the sample before photolysis and the stored spectrum and thus represents a $\mathrm{CO}$-reduced minus $\mathrm{CO}$-reduced baseline. The sample was then photolysed in situ with successive flashes from a $200 \mathrm{~J}$ lamp. Trace $(b)$ is the spectrum of the difference between the photolysed sample (10 flashes) and the CO-reduced spectrum in the memory. The inset shows the effect of increasing the number of flashes on the Soret absorbance changes. The suspension of cells was from an exponentially growing culture and contained approx. $8 \mathrm{mg}$ protein $\mathrm{ml}^{-1}$. 
An advantage of the method used here, however, is that other CO-binding pigments present in intact cells and observed in conventional $\mathrm{CO}$-reduced minus reduced difference spectra, notably cytochrome $d\left(a_{2}\right)$, are excluded from the photodissociation spectrum. Cells grown aerobically under our conditions contain small but measurable amounts of cytochromes $a_{1}$ and $d$ (Poole et al., 1980; R. I. Scott \& R. K. Poole, unpublished results). Using $\mathrm{O}_{2}$-limited cells, which contain elevated levels of these cytochromes, we (Poole \& Chance, 1980) have shown that, although cytochrome $d$ binds $\mathrm{CO}$ and the CO remains bound during the low temperature trapping protocol, it can only be identified in difference spectra of the type shown in Fig. 1 in the presence of $\mathrm{O}_{2}$. The reduced minus $\mathrm{CO}$-reduced spectrum of cytochrome $d$ exhibits a small Soret band that somewhat overlaps with that of cytochrome $o$ but shows distinct features in the red region of the spectrum, namely a peak at $623 \mathrm{~nm}$ and a deep trough at $637 \mathrm{~nm}$ at room temperature (Poole \& Chance, 1980). These bands are clearly absent from Fig. 1 .

A possible explanation is that, even at temperatures as low as -100 or $-130^{\circ} \mathrm{C}$, the rate of recombination of the dissociated $\mathrm{CO}$, when competitive ligands such as $\mathrm{O}_{2}$ are absent, is too fast to be detectable within the first scan after photolysis. For the present purpose, the important point is that the assay of cytochrome $o$ is not confounded by other CO-binding pigments.

Also absent are absorption bands (expected as troughs at 404, 556 and $602 \mathrm{~nm}$ ) due to the CO complex of sulphite reductase haemoprotein (Siegel et al., 1973). The novel haem ('sirohaem') of this enzyme exhibits a rapid binding with $\mathrm{CO}$ to form a photodissociable complex but the CO reactivity of the holoenzyme is sluggish (Murphy et al., 1974).

The dependence of the magnitude of the spectral bands on the concentration of cells in the cuvette was investigated. At cell concentrations up to about $10 \mathrm{mg}$ protein $\mathrm{ml}^{-1}$, the intensities of the $\alpha, \beta$ and $\gamma$ (Soret) bands in photodissociation spectra were directly proportional to cell concentration, the ratio of the bands being approx. $1: 1: 22$. This is in reasonable agreement with the figure of 26 given by Daniel (1970) for the ratio of Soret peak $(417-432 \mathrm{~nm})$ to $\alpha$ peak (551-568 nm). At higher cell concentrations, the intensities of the 535 and $570 \mathrm{~nm}$ bands remained proportional to cell concentration but the Soret to $\alpha$ peak ratio decreased rapidly, presumably due to stray light problems under conditions of low light transmission. All assays of cytochrome $o$ reported subsequently were performed with cell suspensions containing $<10 \mathrm{mg}$ protein $\mathrm{ml}^{-1}$.

\section{Accumulation of cytochrome o during the cell cycle}

A semilogarithmic plot of the amount of cytochrome $o$ per cell as a function of mean cell volume can be well-fitted by a straight line (Fig. 2) with a high correlation coefficient $(r=$ 0.98 ). We ascribe the small deviations from this pattern to experimental error. An estimate of the error inherent in the cytochrome assay was obtained by dividing a cell suspension into eight identical portions and subjecting each to the assay procedure. The coefficient of variation $(100 \times$ standard deviation/mean) of the measured $\gamma$ absorption bands was $3 \%$. Taken with the error inherent in the cell count determinations, also estimated to be about $3 \%$, none of the experimental data points can be considered to be significantly removed from the fitted line.

The zonal fractionation procedure (Scott et al., 1980) resolves an exponentially growing culture of cells into size classes that vary by greater than 2 -fold. We have used the approximation of Kubitschek et al. (1967) to determine the average volumes of neonatal cells $\left(\bar{V}_{\mathrm{b}}\right)$ and incipient cells $\left(\bar{V}_{\mathrm{d}}\right)$ where $\bar{V}_{\mathrm{b}}=\bar{V} \ln 2=\bar{V}_{\mathrm{d}} / 2$, and $\bar{V}$ is the mean volume of cells in the unfractionated population in the rotor. The values for $\bar{V}_{\mathrm{b}}$ and $\bar{V}_{\mathrm{d}}$, respectively, are indicated by the vertical dashed lines in Fig. 2 and are assumed to represent the limits of an idealized cell cycle in which age is proportional to cell volume. The amount of cytochrome $o$ per cell increases $1 \cdot 87$-fold during this period. 


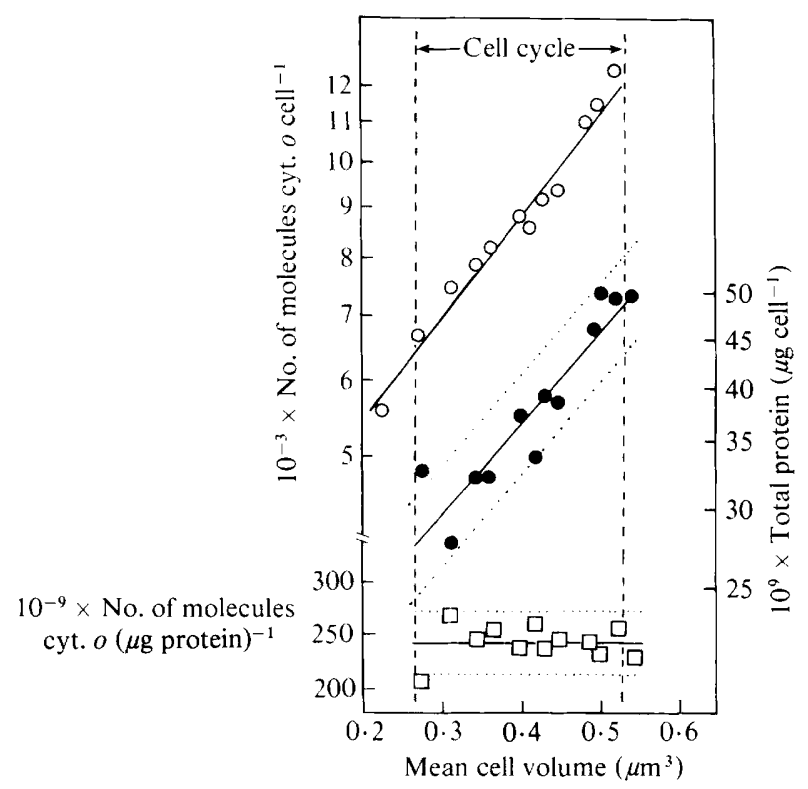

Fig. 2. The accumulation of cytochrome $o$ and total cell protein during the cell cycle. Cytochrome $o$ amounts were calculated from measurements of the Soret absorption bands in photodissociation spectra recorded at $-100^{\circ} \mathrm{C}$. The lines fitted to the data for amounts of cytochrome $o$ per cell $(O)$ and total protein per cell $(-)$ are those of best fit, the correlation coefficients, $r$, being 0.98 and 0.92 , respectively. The line fitted to the data for amount of cytochrome $o(\mu \mathrm{g} \text { protein })^{-1}(\square)$ represents the mean value; the coefficient of variation $(100 \times$ standard deviation $/$ mean $)$ is $7.0 \%$. The vertical dashed lines define a doubling in mean cell volume and indicate the average cell volume at birth and division, respectively. assuming that growth in cell volume is linear through the cell cycle. Where shown, pairs of dotted lines indicate the extent of two standard deviations from the fitted curves.

In agreement with our previous results (Scott et al., 1980), total protein per cell increased smoothly during the cell cycle (1.77-fold increase). The data points have been fitted by an exponential increase (correlation coefficient, $r=0.92$ ). The dotted lines above and below the fitted line show the extent of two standard deviations. As is also shown in Fig. 2, the amount of cytochrome $o$ per cell represents a constant (and small) proportion of total cell protein throughout the cell cycle.

\section{CO binding to cytochrome o during the cell cycle}

By raising the temperature of the sample, the rate of recombination of $\mathrm{CO}$ with the reduced oxidase can be measured. In all cell cycle fractions examined, $\mathrm{CO}$ recombination was observed and this recombination was fully reversible by further photolysis. Examples of the spectra and kinetic traces obtained are given by Poole et al. (1979a,b, 1980). In two experiments in which the rate of recombination was measured at $-65^{\circ} \mathrm{C}$ in successive cell cycle fractions it was found to be essentially constant during the cycle. The mean half-times for the reaction with $\mathrm{CO}$ were $3.61 \mathrm{~min}$ (standard deviation 0.47 ) and $3.71 \mathrm{~min}$ (standard deviation 0.47 ). The rate observed in cells harvested from an exponentially growing culture and before size fractionation was 3.46 (standard deviation 0.84 ).

\section{DIS C USSION}

There is a mounting body of evidence that the inner membrane components of $E$. coli are synthesized throughout the cell cycle. Boyd \& Holland (1979) have made careful 
measurements of protein synthesis in separated inner and outer membranes during the cell cycle and shown that the previously reported doubling in the rate of synthesis of surface proteins (Churchward \& Holland, 1976) is restricted to the bulk outer membrane fraction. This pattern was confirmed by measuring directly the rate of synthesis of an individual outer membrane protein. Total protein and bulk inner membrane protein was synthesized continuously and at an exponentially increasing rate throughout the cycle.

It is unclear as to the extent to which membrane proteins in general, and respiratory chain components in particular, contributed to the proteins identified on two-dimensional gels by Lutkenhaus et al. (1979). However, recent identification of 81 of the $E$. coli proteins separable on such gels shows that the $\alpha$ and $\beta$ subunits of the membrane-bound ATPase are readily visible (Bloch et al., 1980) and may well have been included in the survey of Lutkenhaus et al. (1979).

The methods described in this paper circumvent the problem of identifying proteins on gels and allow us to conclude that the accumulation of an unequivocally identifiable (haemo)protein of the inner membrane is continuous through the cycle. Although we have fitted an exponential increase to the data, we cannot exclude the possibility that accumulation is linear, the rate doubling at some point in each cycle. Discrimination between such patterns is problematic (Mitchison, 1977). Further study of this point must await the purification of cytochrome $o$ from $E$. coli, thus enabling rates of synthesis of the protein to be measured directly. Evidence for continuous accumulation of membrane-bound components of the respiratory chain during the cell cycle also comes from electron paramagnetic resonance spectroscopic assay of ferredoxin-type and high-potential iron-sulphur protein-like clusters (R. K. Poole, R. I. Scott \& H. Blum, unpublished results).

Although in disagreement with Ohki's results for $E$. coli and the discontinuous accumulation of cytochromes in the cell cycle of the fission yeast Schizosaccharomyces pombe (Poole et al., 1974; Poole \& Lloyd, 1974), continuous accumulation of cytochromes has been observed previously in other bacteria (Wraight et al., 1978) and yeast (Cottrell et al., 1975). The underlying mechanisms of these patterns and their physiological consequences have not been adequately explored. In particular, their correlation with changes in respiration rates remains to be established. The results presented here demonstrate that the oxidase that continuously accumulates is functionally active in ligand binding throughout the cell cycle. Extension of previous work in this laboratory on changes in respiratory activity during the cell cycle of $E$. coli (Poole, 1977) is now under way in an attempt to correlate the pattern of respiratory increase in the cell cycle of succinate-grown cells with changes in the amounts and function of respiratory chain components.

This work was supported by the Science Research Council through research grants GR/A/2252.5 and GR/A/87449 to R.K.P. We also thank the Sargeaunt Travel Fund of Queen Elizabeth College for a grant to R.I.S., and numerous colleagues at the Johnson Research Foundation for hospitality and help.

\section{REFERENCES}

Bloch, P. L., Phillips, T. A. \& Neidhardt, F. C. (1980). Protein identifications on O'Farrell two dimensional gels: locations of 81 Escherichia coli proteins. Journal of Bacteriology 141, 1409-1420.

Boyd, A. \& Holland, I. B. (1979). Regulation of the synthesis of surface protein in the cell cycle of $E$. coli B/r. Cell 18, 287-296.

Castor, L. N. \& Chance, B. (1959). Photochemical determinations of the oxidases of bacteria. Journal of Biological Chemistry 234, 1587-1592.

Chance, B. $(1953 a)$. The carbon monoxide compounds of the cytochrome oxidases. II. Photodissociation spectra. Journal of Biological Chemistry 202. 397-406.
Chance, B. $(1953 b)$. The carbon monoxide compounds of the cytochrome oxidases. I. Difference spectra. Journal of Biological Chemistry 202, 383-396.

Chance, B. \& Graham, N. (1971). A rapid scanning dual wavelength spectrophotometer. Review of Scientific Instruments 42, 941-945.

Chance, B., Smith, L. \& Castor, L. (1953). New methods for the study of the carbon monoxide compounds of respiratory enzymes. Biochimica et biophysica acta 12, 289-298.

Chance, B., Graham, N. \& Legallais, V. (1975). Low temperature trapping method for cytochrome 
oxidase oxygen intermediates. Analytical Biochemistry 67, 552-579.

Churchward, G. G. \& Holland, I. B. (1976). Envelope synthesis during the cell cycle in Escherichia coli B/r. Journal of Molecular Biology 105, 245-261.

Cottrell, S. F., Rabinowitz, M. \& Getz. G. S. (1975). Cytochrome synthesis in synchronous cultures of the yeast Saccharomyces cerevisiae. Journal of Biological Chemistry 250, 4087-4094.

DANIEL, R. M. (1970). The electron transport system of Acetobacter suboxydans with particular reference to cytochrome o. Biochimica et biophysica acta $\mathbf{2 1 6}$, 328-341.

Herbert, D., Phipps, P. J. \& Strange, R. E. (1971). Chemical analysis of microbial cells. Methods in Microbiology 5B, 209-344.

Koch, A. L. \& Blumberg, G. (1976). Distribution of bacteria in the velocity gradient centrifuge. Biophysical Journal 16, 389-405.

KubitscheK, H. E., Bendigkeit, H. E. \& LoKen, M. R. (1967). Onset of DNA synthesis during the cell cycle in chemostat cultures. Proceedings of the National Academy of Sciences of the United States of America 57, 1611-1617.

Lutkenhaus, J. F., Moore, B. A., Masters, M. \& DonACHIE, W. D. (1979). Individual proteins are synthesized continuously throughout the Escherichia coli cell cycle. Journal of Bacteriology 138, 352-360.

Mitchison, J. M. (1977). Enzyme synthesis during the cell cycle. In Cell Differentiation in Microorganisms, Plants and Animals, pp. 377-401. Edited by L. Nover \& K. Mothes. Amsterdam: North Holland Publishing Co.

Mosteller, R. D., Goldstein, R. V. \& Nishimoto, K. R. (1980). Metabolism of individual proteins in exponentially-growing Escherichia coli. Journal of Biological Chemistry 255, 2524-2532.

Murphy, M. J., Siegel, L. M. \& Kamin, H. (1974). Reduced nicotinamide adenine dinucleotide phosphate-sulphite reductase of enterobacteria. VI. The reaction of carbon monoxide with the Escherichia coli holoenzyme, the haemoprotein and free sirohaem. Journal of Biological Chemistry 249 , 1610-1614.

OнкI, M. (1972). Correlation between metabolism of phosphatidylglycerol and membrane synthesis in Escherichia coli. Journal of Molecular Biology $\mathbf{6 8}$, 249-264.

PoOLE, R. K. (1977). The influence of growth substrate and capacity for oxidative phosphorylation on respiratory oscillations in synchronous cultures of Escherichia coli K12. Journal of General Microbiology 99, 369-377.

PoOLE, R. K. (1980). Temporal diversity of bacterial respiratory systems. Membrane and respiratory development during the cell cycle. In Diversity of Bacterial Respiratory Systems (in the Press). Edited by C. J. Knowles. Boca Raton, Fla: CRC Press.

Poole, R. K. \& Chance, B. (1980). Intermediates in the reaction with oxygen of cytochrome $d$ in oxygen-limited Escherichia coli. In First European Bioenergetics Conference Short Reports, pp. 107108. Bologna: Pàtron Editore.

Poole, R. K. \& Lloyd, D. (1974). Changes in respiratory activities during the cell cycle of the fission yeast Schizosaccharomyces pombe $972 \mathrm{~h}^{-}$ growing in the presence of glycerol. Biochemical Journal 144, 141-148.

Poole, R. K., Lloyd, D. \& Chance, B. (1974). The development of cytochromes during the cell cycle of a glucose-repressed fission yeast, Schizosaccharomyces pombe $972 \mathrm{~h}^{-}$. Biochemical Journal 138, 201-210.

Poole, R. K., Waring, A. J. \& Chance, B. (1979 a). Evidence for a functional oxygen-bound intermediate in the reaction of Escherichia coli cytochrome $o$ with oxygen. FEBS Letters 101, 56-58.

Poole, R. K., Waring, A. J. \& Chance, B. $(1979 b)$. The reaction of cytochrome $o$ in Escherichia coli with oxygen. Low-temperature kinetic and spectral studies. Biochemical Journal 184, 379-389.

Poole, R. K., Scott, R. I. \& Chance, B. (1980). Low-temperature spectral and kinetic properties of cytochromes in Escherichia coli $\mathrm{K} 12$ grown at lowered oxygen tension. Biochimica et biophysica acta 591, 471-482.

ScotT, R. I. \& Poole, R. K. (1980). A re-examination of the cytochromes of Escherichia coli $\mathrm{K} 12$ by using fourth-order finite difference analysis. Society for General Microbiology Quarterly 7, 86.

ScotT, R. I., Gibson, J. F. \& Poole, R. K. (1980). Adenosine triphosphatase activity and its sensitivity to Ruthenium Red oscillate during the cell cycle of Escherichia coli K12. Journal of General Microbiology 120, 183-198.

ShIPp, W. S. (1972). Cytochromes of Escherichia coli. Archives of Biochemistry and Biophysics 150, 459-472.

Siegel, L. M., Murphy, M. J. \& Kamin, H. (1973). Reduced nicotinamide adenine dinucleotide phosphate-sulphite reductase of enterobacteria. I. The Escherichia coli haemoflavoprotein: molecular parameters and prosthetic groups. Journal of Biological Chemistry 248, 25 1-264.

Wraight, C. A., Lueking, D. R., Fraley, R. T. \& KAPLAN, S. (1978). Synthesis of photopigments and electron transport components in synchronous phototrophic cultures of Rhodopseudomonas sphaeroides. Journal of Biological Chemistry 253, $465-471$. 